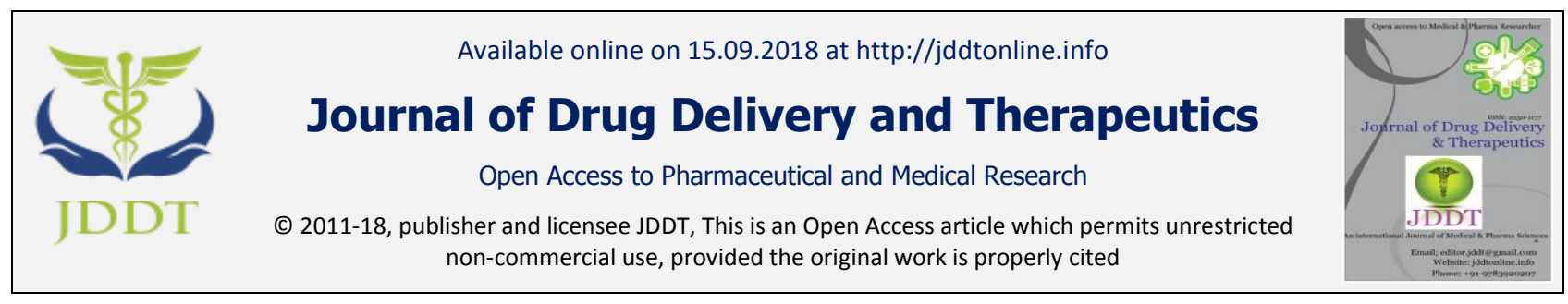

Open $\odot$ Access

Research Article

\title{
SOLUBILITY ENHANCEMENT, FORMULATION DEVELOPMENT AND EVALUATION OF IMMEDIATE RELEASE TABLET OF ANTIHYPERTENSIVE DRUG TADALAFIL
}

\author{
Sisodiya Mayuri $^{1 *}$, Saudagar Ravindranath ${ }^{2}$ \\ ${ }^{1 *}$ Department of Quality Assurance Techniques, R. G. Sapkal College of Pharmacy, Anjaneri, Nashik-422213, Maharashtra, India \\ ${ }^{2}$ Department of Pharmaceutical Chemistry, R. G. Sapkal College of Pharmacy, Anjaneri, Nashik- 422213, Maharashtra, India
}

\begin{abstract}
The objective of the study was to enhance the solubility and dissolution rate of Tadalafil using hydrophilic carriers such as polyvinyl pyrrolidone K-30 (PVP), Poloxamer 188, Sodium starch glycolate and compatibility study of Tadalafil with different polymers by FTIR. Characterization of solid dispersion-FTIR, DSC and phase solubility analysis was study to improve the oral bioavailability. Formulation and evaluation of immediate release tablets prepare from solubility enhanced Tadalafil. Among the various approaches Solvent evaporation has gained good acceptance in recent years in the industry for enhancing the solubility and dissolution rate of poorly soluble drugs. Poloxamer 188 used as polymer as it is good solubilizing agent. As per the phase solubility studies, a $3^{2}$ factorial study were used to prepare the immediate release tablet and evaluated for the interactions and in vitro drug release. Sodium Starch Glycolate and PVP used as superdisintegrants. The solubility of tadalafil in selected ratios containing tadalafil and Poloxamer 188 solid dispersion prepared by solvent evaporation was determined. From the various ratios 1:0.5 was resulted in a much higher enhancement (9.75folds). Fourier transform infrared spectroscopy (FT-IR) and differential scanning calorimetry (DSC) studies conducted, explain overall drug and excipients compatibility. More than $90 \%$ of tadalafil was released from IR tablet within 30 min. There is enhancement of the solubility rate if tadalafil by solid dispersion with Poloxamer 188 prepared by solvent evaporation method. The drug was characterized for its organoleptic properties and the results obtained. The compatibility studies of the drug and polymers showed that there was no incompatibility between them. Wet granulation method showed that, the desirable flow properties for the compression into tablets. Tablets were prepared using wet granulation method resulted into simple, cheap, more suitable method for the manufacturing immediate release dosage form.
\end{abstract}

Keywords: Immediate release tablet, Superdisintigrants, Wet granulation method, Poloxamer 188.

Article Info: Received 23 July, 2018; Review Completed 18 Aug 2018; Accepted 21 Aug 2018; Available online 15 Sep 2018

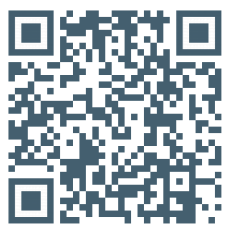

\section{Cite this article as:}

Sisodiya M, Saudagar R, Solubility enhancement, formulation development and evaluation of immediate release tablet of antihypertensive drug tadalafil, Journal of Drug Delivery and Therapeutics. 2018; 8(5):294-302 DOI: http://dx.doi.org/10.22270/jddt.v8i5.1872

*Address for Correspondence:

Mayuri Sisodiya, Department of Quality Assurance Techniques, R. G. Sapkal College of Pharmacy, Anjaneri, Nashik-422213, Maharashtra, India

\section{INTRODUCTION}

Hypertension or high blood pressure (BP) is a medical condition, in which the $\mathrm{BP}$ in the arteries is persistently elevated. BP is the force of blood pushing up against the wall of blood vessels (arteries and veins). Important organs affected are heart leading to heart attack or heart failure, brain leading to stroke, kidney leading to chronic renal failure, eyes leading to bleeding in retina, loss of vision, and nerve damage ${ }^{1}$. WHO rates the hypertension as one of the most important causes of premature death in worldwide. According to the WHO hypertension is a highly prevalent cardiovascular disease. In India, hypertension is the most prevalent chronic disease. The prevalence of hypertension ranges from $20 \%$ to $40 \%$ in urban adults and $12-17 \%$ among rural adults ${ }^{2}$. Oral route is most common route of administration of drug because of its systemic effect, 
patient compliance, less expensive to manufacture. Tablet provides high precision dosing. In most of the cases immediate on set of action is required as compare to conventional therapy. To achieve the rapid onset of action and eliminate the drawbacks of conventional therapy immediate release dosage form is now a days popular oral dosage form. Basic approach used in development is the use of superdisintegrants which provide rapid disintegration of tablet after administration $^{3}$. This research work is concerned with the formulation and evaluation of immediate release tablet of Tadalafil to provide immediate relief from hypertension. A solubility and dissolution are the key parameters for the therapeutic effect of a drug. Solubility is one of the important parameter to achieve desire concentration of drug in systemic circulation for pharmacological response ${ }^{4}$.

More than $92 \%$ of the drug listed in U.S. pharmacopoeia which is having low solubility. It is commonly recognized in the pharmaceutical industry that on average more than $40 \%$ of newly discovered drug candidates are having poor solubility. Micronization, Nanonization, salt formation, use of surfactants, solid dispersion are the several methods for enhancement of solubility of the drugs ${ }^{5,6,7}$. Solid dispersion techniques can be used to increase dissolution and absorption of several insoluble drugs ${ }^{8,9}$. To date, a number of drugs are not showing complete therapeutic effect because of their poor solubility and dissolution, which in turn leads to poor bioavailability of the drug ${ }^{10,11}$. So, in the modern days, top most importance is given for increasing the dissolution rate of poorly soluble drugs, which enhances their bioavailability. Solid dispersions are one of the most promising strategies to improve the solubility and dissolution rate of poorly water-soluble drugs ${ }^{12}$. By reducing the drug particle size to the absolute minimum, and hence, thereby improving drug wettability, bioavailability may can be significantly improved. They are usually presented as amorphous products the term "'solid dispersion'" has been utilized to describe a family of dosage forms, whereby the drug is dispersed in a biological inert matrix, usually with a view in order to enhancing the oral bioavailability. More specifically, Chiou and Regelman (1971), defined these systems as "the dispersion of one or more active ingredient in an inert matrix at solid-state prepared by the melting (Fusion), solvent or melting solvent method"13,14. Tadalafil is an inhibitor of phosphodiesterase 5 (PDE-5), the enzyme responsible for the degradation of cyclic guanosine monophosphate (cGMP). PAH is associated with the impaired release of nitric oxide by the vascular endothelium in the pulmonary vasculature. Inhibition of PDE-5 by tadalafil increases the concentrations of cGMP, resulting in relaxation of pulmonary vascular smooth muscle cells and vasodilation of the pulmonary vascular bed. Tadalafil is a white or almost white powder and it is poorly soluble in water. Since the dissolution rate of the drug from surface is affected by the carrier has an ultimate influence on the dissolution of the dispersed drug. Hence hydrophilic carrier polaxmer188 was used as carriers for converting Tadalafil into solid dispersions in this study.

\section{MATERIAL AND METHOD}

Tadalafil was obtained as gift sample from Cipla Pharmaceutical, Ltd, Mumbai. Polaxmer-188 from Glenmark Pharmaceutics, Sinnar Nashik, methanol from Research-Lab Fine Chem. Industry, Mumbai, PVP and Sodium starch glycolate from Research-Lab Fine Chem. Industry-Mumbai. lactose, microcrystalline cellulose, Magnesium stearate, talc from Research-Lab Fine Chem. Industry-Mumbai.

\section{Preformulation Study of Drug:}

Preformulation testing is the first step in the rational development of dosage forms of a drug. It can be defined as an investigation of physical and chemical properties of drug substance, alone and when combined with excipients. The overall objective of preformulation testing is to generate information useful to the formulator in developing stable and bioavailable dosage forms, which can be mass-produced ${ }^{15,16}$.

\section{Identification Tests}

\section{Organoleptic Properties:}

The sample of Tadalafil was studied for organoleptic characteristics such as colour, odour and appearance.

\section{Melting Point:}

Melting point of Tadalafil was determined by taking a small amount of sample in a capillary tube closed at one end and placed in melting point apparatus. The melting point was noted in triplicate and average value was noted $^{17}$.

\section{IR Spectroscopy}

The FT-IR spectrum of the obtained sample of drug was compared with the standard FT-IR spectra of the pure drug.

Solubility: The solubility of Tadalafil was checked in different solvents: water, methanol, ethanol, $0.1 \mathrm{~N} \mathrm{HCl}$, $0.1 \mathrm{~N} \mathrm{NaOH}$, and phosphate buffer $6.9 . \mathrm{mL}$ of was added to $10 \mathrm{mg}$ of Tadalafil separately and shaken vigorously for 5 minute and placed in a constant temperature bath for 15 minutes ${ }^{18}$.

Differential Scanning Calorimetry: Differential Scanning Calorimetry (DSC) was performed using differential scanning calorimeter (SW9.2, Mettler Star) equipped with a computerized data station on pure drug tadalafil to determine the melting point and exothermic and endothermic peaks. An empty standard aluminium pan was used as reference. DSC scans were recorded at heating rate of $10^{\circ} \mathrm{C} / \mathrm{min}$ in the temperature range $30^{\circ}$ $300^{\circ} \mathrm{C}$ and $40 \mathrm{ml} / \mathrm{min}$ of nitrogen flow.

Ultraviolet-Visible Spectroscopy: The UV spectrum of Tadalafil was obtained using UV Visible Double Beam Spectrophotometer (V630, Jasco). Accurately weighed $10 \mathrm{mg}$ of the drug was dissolved separately in solvent (methanol) volume was made up to $100 \mathrm{~mL}$ by the respective solvent to obtain a stock solution of final concentration $100 \mu \mathrm{g} / \mathrm{mL}$. Aliquot $(1 \mathrm{~mL})$ of stock solution of Tadalafil was transferred into a series $10 \mathrm{~mL}$ volumetric flask and volume was made up to the mark with the respective solvent to produce the concentration 
range $10 \mu \mathrm{g} / \mathrm{mL}$. The resultant solution was scanned from 200 to $400 \mathrm{~nm}$ and the spectrum was recorded to obtain the value of maximum wavelength. The stock solution of $100 \mu \mathrm{g} / \mathrm{mL}$ was used to prepare different dilutions in the range of $2-20 \mu \mathrm{g} / \mathrm{mL}$. The absorbance values for resulting solutions were measured at $\lambda \max$ using respective solvent as blank by UV-visible spectrophotometer $^{19}$.

\section{Compatibility Study:}

Physicochemical compatibility study: Compatibility study of drug and polymers was done in vials for 1month at $40^{\circ} \mathrm{C}$. The drug to polymer ratio was taken as 1:0.5, 1:1 and 1:2. The vials were daily checked for gas formation, colour change, liquefaction and caking by visual inspection and results were noted down.

Preparation of solid dispersions of Tadalafil: Solid dispersions were prepared by solvent evaporation technique. Physical mixtures of Tadalafil were prepared by mixing Tadalafil and polaxomer188 in sufficient amount of methanol individually in a glass mortar by trituration for 30 minutes.

Table 1: Composition of various Solid dispersion

\begin{tabular}{|l|c|c|}
\hline S.N. & $\begin{array}{c}\text { Composition of Drug } \\
\text { polymer }\end{array}$ & Ratios (w/w) \\
\hline 1 & Tadalafil: Poloxamer 188 & $1: 0.5$ \\
2 & Tadalafil: Poloxamer 188 & $1: 1$ \\
3 & Tadalafil: Poloxamer 188 & $1: 2$ \\
\hline
\end{tabular}

\section{Evaluation of prepared Solid Dispersions:}

Production yield: The production yield formulation was calculated using the weight of final product after drying with respect to the initial total weight of the drug and carrier used for the preparation of complex.

\section{Drug content:}

About $10 \mathrm{mg}$ drug equivalent were weighed accurately and transferred to $100 \mathrm{ml}$ volumetric flask. From this stock solution $(100 \mu \mathrm{g} / \mathrm{ml}), 1 \mathrm{ml}$ was withdrawn and further diluted upto $10 \mathrm{ml}$ with methanol. This solution was used for the assay for drug content by UV spectrophotometer at $284 \mathrm{~nm}$. Concentration of drug in stock solution was calculated by using calibration curve and from which percentage drug content in complex was calculated.

\section{Fourier Transform Infrared Spectroscopy}

Compatibility study was carried out by using Fourier transform infrared spectrophotometer. FTIR study was carried on pure drug and solid dispersion (SD). SD was prepared, and samples were stored at 400C for 1month. The infrared absorption spectrum of drug and SD of drug was recorded with a $\mathrm{KBr}$ disc over the wave number 4000 to $400^{\mathrm{cm}-1}$.

\section{Differential Scanning Calrimetry (DSC):}

Thermal analysis was performed using a differential scanning calorimeter equipped with a computerized data station. The sample of pure drug and SD of drug was weighed and heated at a scanning rate of $10^{\circ} \mathrm{C} / \mathrm{min}$ between $30^{\circ} \mathrm{C}$ and $300^{\circ} \mathrm{C}$ and $40 \mathrm{ml} / \mathrm{min}$ of nitrogen flow. DSC analysis gives an idea about the interaction of various materials at different temperatures. It also allows detecting possibility degradation of the material.

\section{$\mathrm{X}$ ray Diffraction:}

For the structural, crystal, and physical state characterization of Tadalafil, X-Ray diffraction studies were performed for pure drug, Tadalafil. XRD study was carried out with Bruker AXS D8 Advance with Vertical, Theta/2 geometry using copper target, a voltage of $40 \mathrm{kv}$ and a current of $35 \mathrm{~mA}$. The scanning was done over $2 \theta$ range of $3^{\circ}$ to $135^{\circ}$.

\section{Formulation and Development of Tablet of solid dispersion}

Method of preparation of Granules: Tadalafil dispersions were taken in mortar and pestle along with suitable diluents and mixed constantly until a dry is mix obtained (before mixing both the diluents and dispersions were allowed to pass through \# 22 mesh). The binder was dissolved in hot purified water and stirred constantly until the complete PVP goes into solution. Binder solution was added to above dry mix and mixed slowly. Extra water was added till required consistency of mass is obtained and sifted through \#22 mesh to obtain granules. Granules were dried in hot air oven and sifted through \#24 to obtain uniform sized granules. The sifted granules were taken and blended with Talc and disintegrant for $10 \mathrm{~min}$. Magnesium stearate was sifted and added to above blend and lubricated for 5 mins. The blend was compressed into tablet using punches and suitable dies with a tablet weight of $250 \mathrm{mg}$.

Table 2: Composition of formulations as per $3^{2}$ full factorial design

\begin{tabular}{|l|c|c|c|c|c|c|c|c|c|}
\hline Formulation Code & F1 & F2 & F3 & F4 & F5 & F6 & F7 & F8 & F9 \\
\hline Ingredient & \multicolumn{7}{|c|}{ Mg } \\
\hline SD & 28 & 28 & 28 & 28 & 28 & 28 & 28 & 28 & 28 \\
CCS & 7.5 & 10 & 12.5 & 7.5 & 10 & 12.5 & 7.5 & 10 & 12.5 \\
SSG & 5 & 5 & 5 & 12.5 & 12.5 & 12.5 & 20 & 20 & 20 \\
PVP & 7.5 & 7.5 & 7.5 & 7.5 & 7.5 & 7.5 & 7.5 & 7.5 & 7.5 \\
Magnesium Stearate & 10 & 10 & 10 & 10 & 10 & 10 & 10 & 10 & 10 \\
MCC & 50 & 50 & 50 & 50 & 50 & 50 & 50 & 50 & 50 \\
Lactose & 141 & 138.5 & 136 & 133.5 & 131 & 128.5 & 126 & 123 & 121 \\
Talc & 1 & 1 & 1 & 1 & 1 & 1 & 1 & 1 & 1 \\
\hline
\end{tabular}


Evaluation of Granules: The flow properties of granules (before compression) were characterized in terms of angle of repose, tapped density, bulk density, Carr's index and Hausner's ratio.

Formulation of Tadalafil Tablets: Tablets each containing 20mg of TD were formulated employing TD co-evaporate of polaxmer188 (1:0.5) along with the usual tablet excipients. The formula of TD tablets is given in Table 2. TD tablets were prepared by conventional wet granulation method.

\section{Evaluation of Tablet:}

Thickness: The thickness of tablet is important for uniformity of tablet size. The thickness of the tablets was determined using a Digital Vernier Calliper. Three tablets from each batch were used.

Hardness: For each formulation, the hardness of three tablets was checked using the Monsanto hardness tester (LAB- HOSP).

Friability: Friability is the measure of tablet strength. In this test, number of tablets subjected to combined effect of shock abrasion by utilizing a plastic chamber which revolves at a speed of $25 \mathrm{rpm}$, dropping the tablets at a distance of 6 inches in each revolution. A sample of preweighed tablets was placed in Roche Friability tester (Kumar Mfg. Ltd.). This was then operated for 100 revolutions. The tablets then de-dusted and reweighed. Permitted friability limit is $1.0 \%$. Tablets were then weighed, and friability values were determined.

Uniformity of weight: Twenty tablets were weighed individually. Average weight was calculated from the total weight of all tablets. The individual weights were compared with the average weight. The percentage difference in the weight variation should be within the acceptable limits $( \pm 5 \%)$. The percent deviation was calculated using the following formula.

Drug content uniformity: Five tablets were weighed individually and powdered. The powder equivalent to 20 $\mathrm{mg}$ of tadalafil was weighed and dissolved in methanol. The volume was made to 100 with methanol. From this stock solution, $10 \mu \mathrm{g} / \mathrm{ml}$ solution was prepared. The drug contents of the resulting solution were calculated from UV absorbance at $284.0 \mathrm{~nm}$.

Disintegration time: The in-vitro disintegration studies were carried out using Tablet Disintegration Test apparatus. One tablet was placed in each of the six tubes of the basket assembly and disk was added to each tube. This assembly was then suspended in one-liter beaker containing water maintained at $37 \pm 2^{\circ} \mathrm{C}$. The basket was then moved up and down through a distance of 5 to $6 \mathrm{~cm}$ at a frequency of 28 to 32 cycles per minutes. The time required for complete disintegration of the tablet was recorded. The test was performed for tablets of all type of formulation (F1-F9).

In-Vitro drug release study: An in-vitro drug release studies of the prepared nine formulations of Conventional tablet were conducted for a period of 60 minutes using an eight station USP type 2 apparatus (paddle type). The agitation speed was $50 \mathrm{rpm}$. Tadalafil tablet were added to $900 \mathrm{ml}$ of $0.1 \mathrm{~N} \mathrm{HCL}$ at $37 \pm 0.5^{\circ} \mathrm{C}$. $5 \mathrm{ml}$ aliquots were withdrawn at time intervals of 5,10 , $15,20,25,30 \mathrm{~min}$ and filtered through Whatmans filter paper. An equal volume of fresh dissolution medium was replaced to maintain the volume of dissolution medium. The filtered samples were analysed spectrophotometrically at $284.0 \mathrm{~nm}$. Cumulative percentage of labelled amount of drug released was calculated.

Stability study: The optimized formulation was wrapped in aluminium foil and subjected to $40 \pm 2^{\circ} \mathrm{C}$ temperature and $75 \pm 5 \% \mathrm{RH}$ in oven for the period of three months. The formulation was analyzed for organoleptic characteristics, thickness, hardness, drugcontent, disintegration time, weight variation and dissolution. In any rational design and evaluation of dosage forms for drugs, the stability of the active component is the major criteria in determining their acceptance or rejection. Stability studies were carried out as per ICH Q1A guidelines. During the stability studies, the product is exposed to normal conditions of temperature and humidity. The optimized Tadalafil formulations were subjected for stability studies.

\section{RESULTS AND DISCUSSION}

\section{Preformulation Study:}

Preformulation testing is the first step in the rational development of dosage forms of a drug. It can be defined as an investigation of physical and chemical properties of drug substance, alone and when combined with excipients. The overall objective of preformulation testing is to generate information useful to the formulator in developing stable and bioavailable dosage forms, which can be mass-produced. Tadalafil is a white or almost white amorphous and odourless powder. Melting point of Tadalafil was found to be $298^{\circ} \mathrm{C}$. It is soluble in methanol and $0.1 \mathrm{~N} \mathrm{HCL}$ and practically insoluble in water.

\section{IR Spectroscopy:}

The FT-IR spectrum of the obtained sample of drug was conducted and compare with the standard FT-IR spectra of the pure drug. 


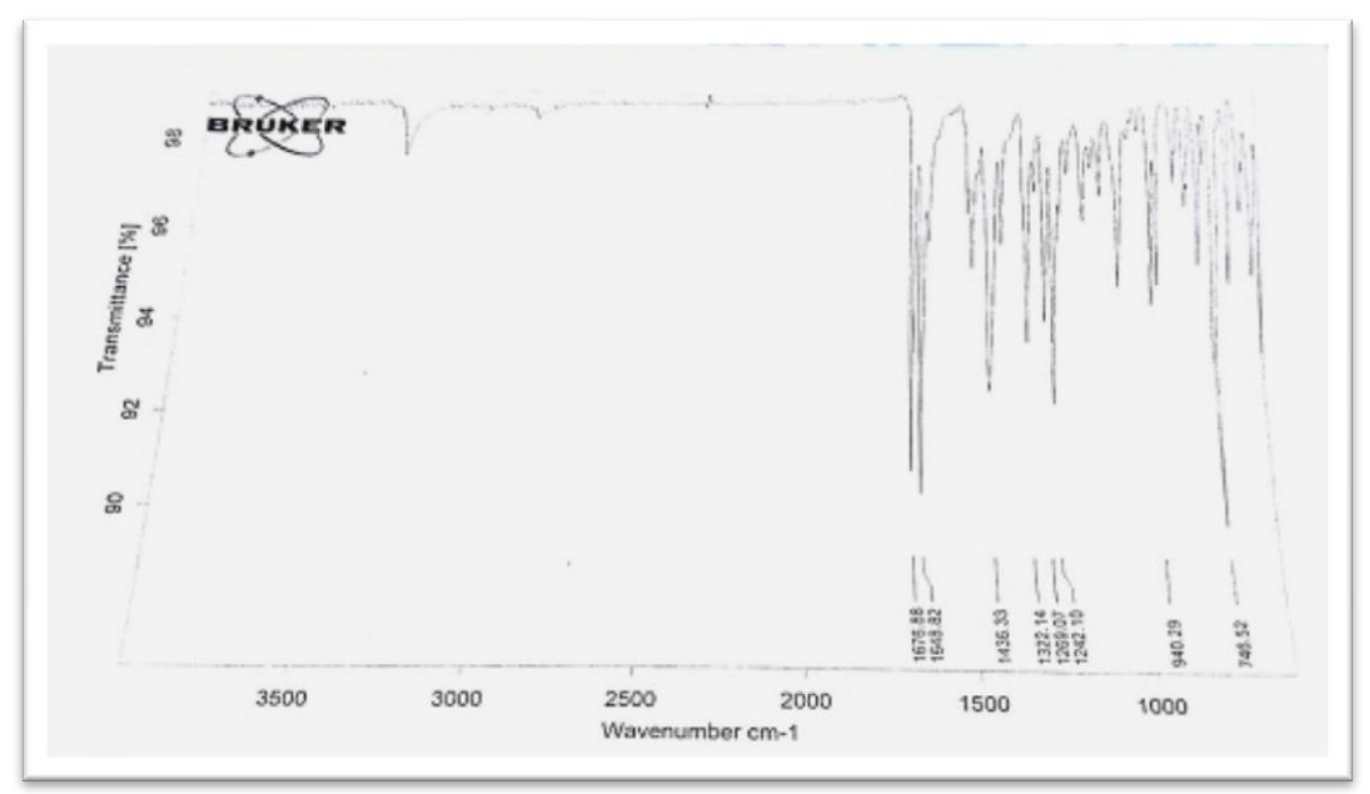

Figure 1: FTIR Spectrum of tadalafil

\section{Differential Scanning Calorimetry (DSC):}

Differential Scanning Calorimetry (DSC) was performed using differential scanning calorimeter (SW9.2, Mettler Star) equipped with a computerized data station on pure drug tadalafil to determine the melting point and exothermic and endothermic peaks. An empty standard aluminium pan was used as reference. DSC scans were recorded at heating rate of $10^{\circ} \mathrm{C} / \mathrm{min}$ in the temperature range $30^{\circ}-300^{\circ} \mathrm{C}$ and 40 $\mathrm{ml} / \mathrm{min}$ of nitrogen flow.

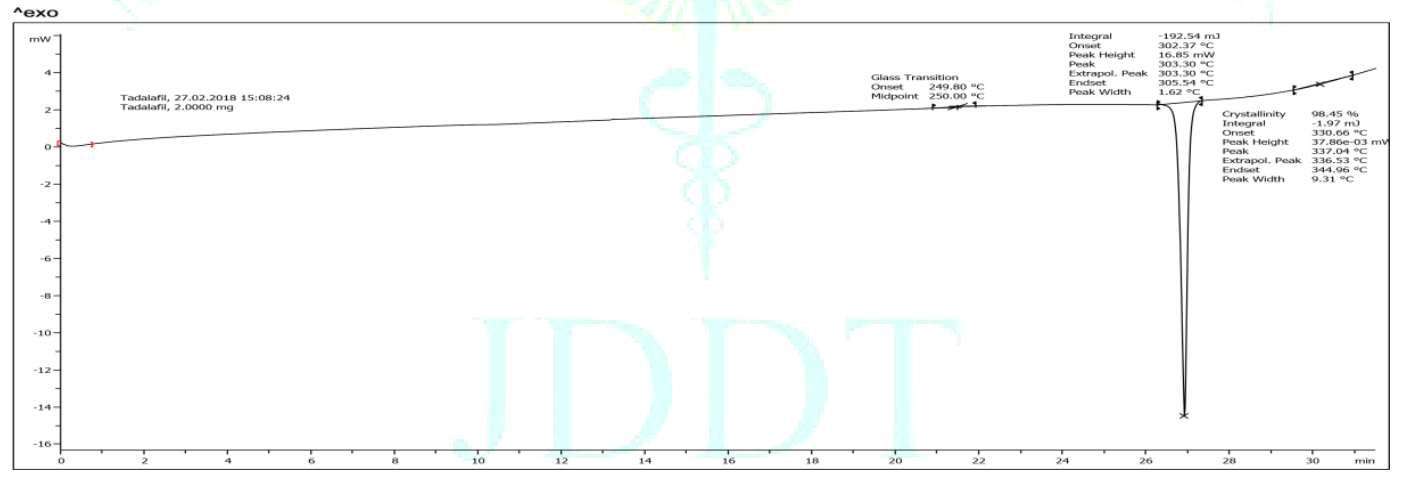

Figure 2: DSC of tadalafil

\section{Characterization of prepared SDs}

The prepared SD was subjected for solubility study and optimized ratio was evaluated for further characterization.

\section{Solubility Study:}

The prepared SD was subjected for solubility studies to evaluate the effect of carrier on the aqueous solubility of TDL were studied and results of phase solubility analysis are shown in Table.3.

Table 3: Result of Phase solubility study

\begin{tabular}{|l|c|l|l|l|l|l|}
\hline Sr. No & $\begin{array}{l}\text { Formulation } \\
\text { Code }\end{array}$ & Drug & Polymer & Ratio & $\begin{array}{l}\text { Solubility(mg/ml) } \\
\pm \text { S.D. }\end{array}$ & $\begin{array}{l}\text { Fold increase } \\
\text { Insolubility (Fold) }\end{array}$ \\
\hline 1. & Drug & TDL & ---- & ---- & 0.250 & 1 -fold \\
2. & SD1 & TDL & PLX 188 & $1: 0.5$ & 0.567 & 9.75 -fold \\
3. & SD2 & TDL & PLX 188 & $1: 1$ & 0.385 & 6.10 -fold \\
4. & SD3 & TDL & PLX 188 & $1: 2$ & 0.128 & 3.90 -fold \\
\hline
\end{tabular}




\section{Drug Content Estimation:}

The selected ratios were subjected to the determination of drug content. The drug content in the selected ratios was found to be in range of 92 to $98 \%$. Almost negligible loss of drug may have occurred probably because preparation of combinations was confined to the very small area of mortar.

\section{Production Yield:}

The production yield of solid dispersion prepared by solvent evaporation method was found to be $86.66 \%$. Any loss in yield can be attributed to the product remaining adhered to the walls of the mortar which could not be retrieved the results of Percentage Yield.

Table 4: Result of Percentage Yield

\begin{tabular}{|c|c|c|c|c|}
\hline Sr. No. & Drug & Polymer & Ratio & Percentage Yield \\
\hline 1. & Tadalafil & PLX 188 & $1: 0.5$ & $86.66 \%$ \\
\hline 2. & Tadalafil & PLX 188 & $1: 1$ & $70 \%$ \\
\hline 3. & Tadalafil & PLX 188 & $1: 2$ & $83.3 \%$ \\
\hline
\end{tabular}

\section{IR Spectroscopy:}

The FT-IR spectrum of the Solid dispersion was conducted and compare with the standard FT-IR spectra of the pure drug.

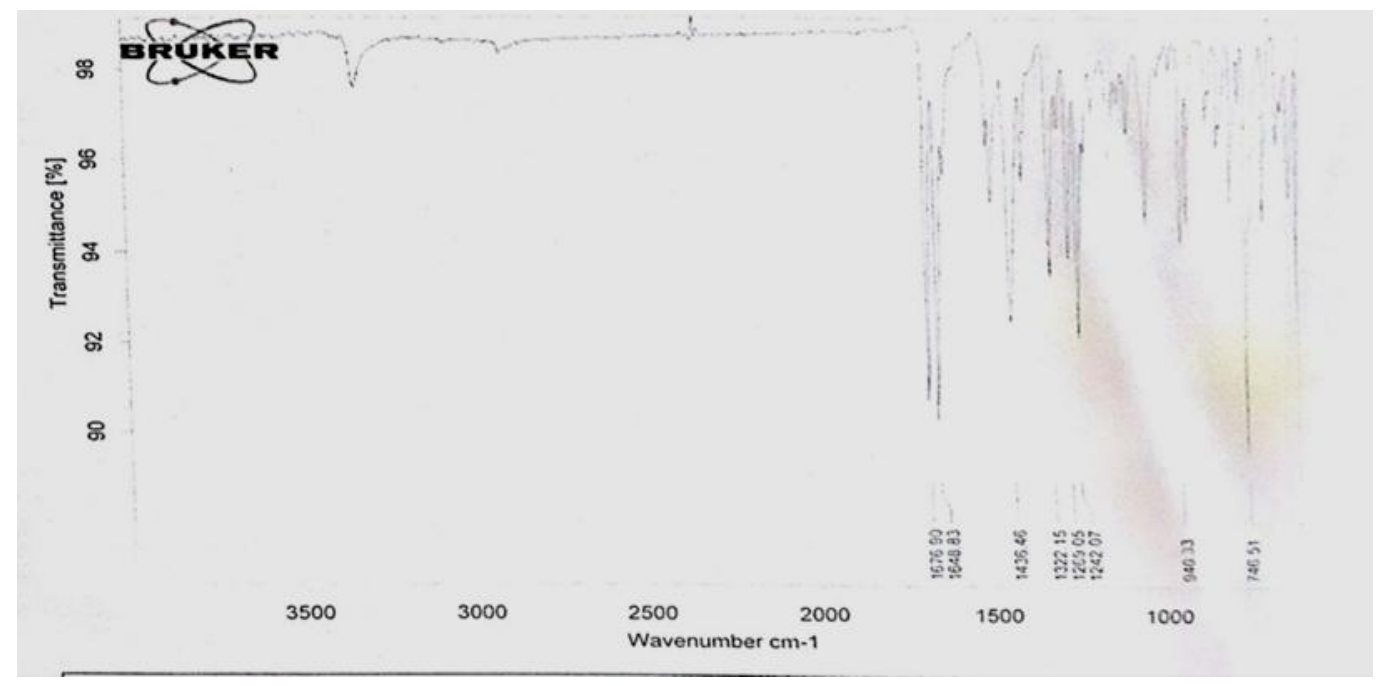

Figure 3: FTIR Spectrum of SD

\section{Differential Scanning Calorimetry (DSC):}

The solid dispersion showed the melting point reduced to $303^{\circ} \mathrm{C}$ from $254{ }^{\circ} \mathrm{C}$ and $60{ }^{\circ} \mathrm{C}$ to $49^{\circ} \mathrm{C}$ and the intensity of the peak in pure drug is reduced. The sharp endothermic peak of pure drug was not observed in solid dispersion, which indicates that the Tadalafil was molecularly dispersed and in amorphous form. This change indicates that the dehydration of pure drug and change in the particle size giving more amorphous type of the product this may help in cleaving the solubility of drug. These shifting of peaks are due to the above experimental reason but not to interaction.

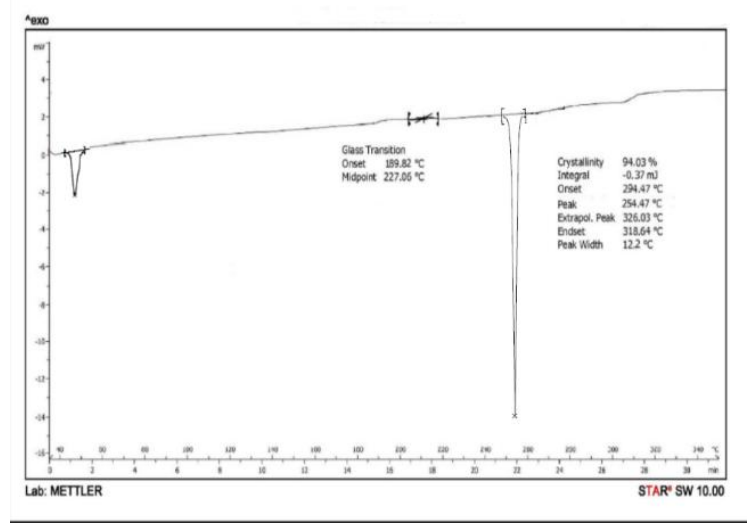

Figure 4: DSC of SD 


\section{X-Ray Diffraction of SD:}

Diffraction spectra of solid dispersion prepared by solvent evaporation method are presented in Fig. 5 respectively. The XRD of Tadalafil shows sharp peaks indicating that the drug is of crystalline nature. While that of solid dispersion shows blunt peaks indicating its amorphous nature. This proves the conversion of crystalline form of drug into amorphous form in solid dispersion. Thus, result of XRD support the findings of the DSC study.

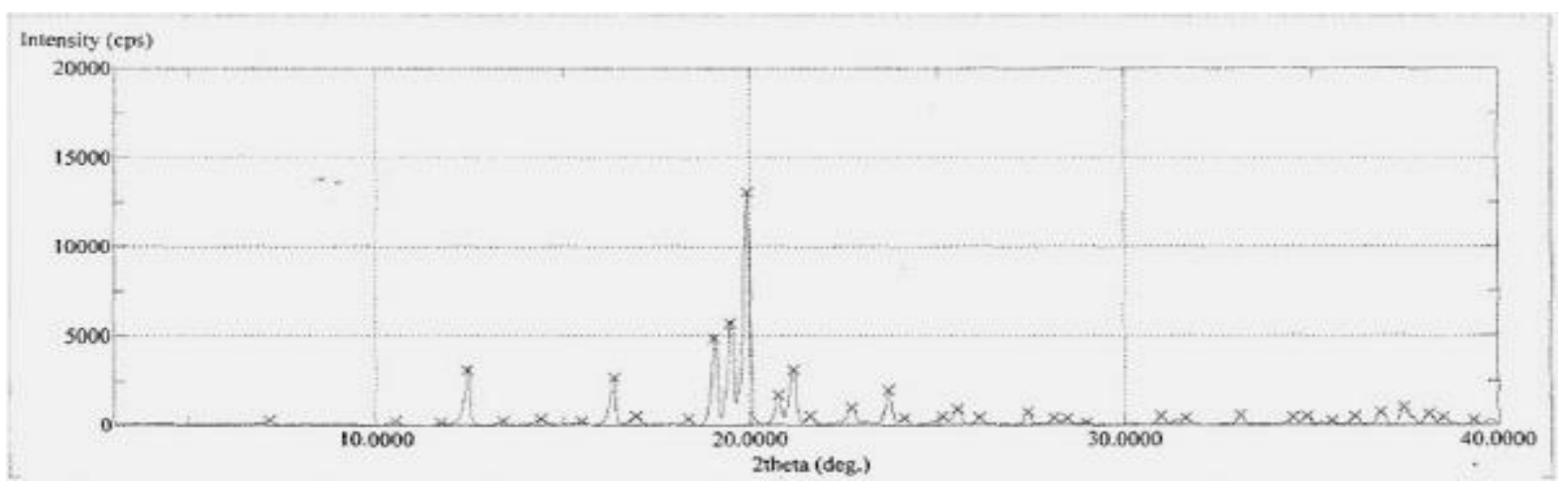

Figure 5: XRD of SD

Evaluation of tablets:

\section{Precompressional evaluation}

Table 5: Precompressional evaluation

\begin{tabular}{|l|c|c|c|c|c|}
\hline $\begin{array}{c}\text { Batch } \\
\text { No. }\end{array}$ & $\begin{array}{c}\text { Bulk density } \\
\left(\mathbf{g m} / \mathbf{c m}^{\mathbf{3}}\right)\end{array}$ & $\begin{array}{c}\text { Tapped density } \\
\left(\mathbf{g m} / \mathbf{c m}^{\mathbf{3}}\right)\end{array}$ & $\begin{array}{c}\text { Compressibility } \\
\text { index (\%) }\end{array}$ & Hausner's ratio & $\begin{array}{c}\text { Angle of } \\
\text { repose(o) }\end{array}$ \\
\hline F1 & $0.399 \pm 0.012$ & $0.4545 \pm 0.040$ & $13 \pm 0.109$ & $1.15 \pm 0.06$ & $23.43 \pm 0$ \\
\hline F2 & $0.3949 \pm 0.017$ & $0.4690 \pm 0.003$ & $15 \pm 0.1063$ & $1.18 \pm 0.06$ & $22.50 \pm 0.19$ \\
\hline F3 & $0.3897 \pm 0.022$ & $0.4413 \pm 0.007$ & $11 \pm 0.12$ & $1.13 \pm 0.03$ & $23 \pm 0.25$ \\
\hline F4 & $0.3949 \pm 0.017$ & $0.4690 \pm 0.03$ & $15 \pm 0.18$ & $1.18 \pm 0.02$ & $28.55 \pm 0.65$ \\
\hline F5 & $0.4017 \pm 0.017$ & $0.4545 \pm 0.040$ & $11 \pm 1.26$ & $1.13 \pm 0.1$ & $25 \pm 0.45$ \\
\hline F6 & $0.3949 \pm 0.017$ & $0.4413 \pm 0.02$ & $10 \pm 0.108$ & $1.11 \pm 0.09$ & $23.5 \pm 0.29$ \\
\hline F7 & $0.3949 \pm 0.017$ & $0.4690 \pm 0.03$ & $15 \pm 0.44$ & $1.18 \pm 0.007$ & $29.55 \pm 0.60$ \\
\hline F8 & $0.3846 \pm 0.001$ & $0.4545 \pm 0.001$ & $15 \pm 1.3288$ & $1.18 \pm 0.01$ & $23.5 \pm 0.96$ \\
\hline F9 & $0.4055 \pm 0.002$ & $0.4690 \pm 0.03$ & $13 \pm 0.9825$ & $1.15 \pm 0.04$ & $28.5 \pm 0.946$ \\
\hline
\end{tabular}

The above results predict that, the Carr's index is in range of $10-15 \%$ which is considered as Ecxellent compression property. Angle of repose less than $30^{\circ}$ gives excellent flow property to the granules blend. Similarly, bulk density and tapped density value was found to be less than one. Hence have good flow property. All these results indicate that, the granules blend possess satisfactory flow and compressibility properties.

\section{Post compressional evaluation:}

Table 6: Postcompressional evaluation

\begin{tabular}{|l|l|l|l|l|c|c|}
\hline $\begin{array}{l}\text { Batch } \\
\text { No. }\end{array}$ & \multicolumn{1}{|c|}{$\begin{array}{c}\text { Thickness } \\
(\mathbf{m m})\end{array}$} & $\begin{array}{l}\text { Hardness } \\
\left(\mathbf{k g} / \mathbf{c m}^{\mathbf{2}}\right)\end{array}$ & Friability $\mathbf{( \% )}$ & $\begin{array}{c}\text { Weight } \\
\text { variation }(\mathbf{m g})\end{array}$ & $\begin{array}{c}\text { Disintegration } \\
\text { Time }\end{array}$ & \% CDR \\
\hline F1 & $4.47 \pm 0.05$ & $3.46 \pm 0.09$ & $1.010 \pm 0.045$ & $245.65 \pm 0.076$ & $1 \mathrm{~min} 32 \mathrm{sec}$ & 85.05 \\
\hline F2 & $4.47 \pm 0.03$ & $2.50 \pm 0.08$ & $0.326 \pm 0.040$ & $248 \pm 0.36$ & $1 \mathrm{~min} 50 \mathrm{sec}$ & 79.65 \\
\hline F3 & $4.50 \pm 0.02$ & $3.06 \pm 0.074$ & $1.063 \pm 0.023$ & $248.2 \pm 0.47$ & $1 \mathrm{~min}$ & 89.1 \\
\hline F4 & $4.34 \pm 0.02$ & $2.73 \pm 0.09$ & $0.531 \pm 0.023$ & $248 \pm 0.047$ & $1 \mathrm{~min} 45 \mathrm{sec}$ & 94.8 \\
\hline F5 & $4.48 \pm 0.03$ & $3.2 \pm 0.06$ & $1.291 \pm 0.046$ & $249 \pm 0.002$ & $54 \mathrm{sec}$ & 92.2 \\
\hline F6 & $4.49 \pm 0.01$ & $2.5 \pm 0.05$ & $0.326 \pm 0.046$ & $248 \pm 0.002$ & $35 \mathrm{sec}$ & 98.6 \\
\hline F7 & $4.47 \pm 0.06$ & $2.6 \pm 0.06$ & $0.266 \pm 0.061$ & $249 \pm 0.003$ & $1 \mathrm{~min} 20 \mathrm{sec}$ & 96.75 \\
\hline F8 & $4.49 \pm 0.03$ & $3.06 \pm 0.1$ & $0.279 \pm 0.040$ & $248 \pm 0.004$ & $45 \mathrm{sec}$ & 89.7 \\
\hline F9 & $4.49 \pm 0.02$ & $2.6 \pm 0.1$ & $1.476 \pm 2.074$ & $249 \pm 0.031$ & $57 \mathrm{sec}$ & 89.70 \\
\hline
\end{tabular}

All the tablet preparations were evaluated for various physical parameters before proceeding further. Tablet weights in all batches varied between 245-250 thickness between 4.47-4.50 and tablet hardness between 2.50- 
3.46. Thus, all the physical parameters of the manually compressed tablets were quite within control. The percentage friability, as depicted in Table was in the range of $0.265-1.476$ to be well within approved range $(<1 \%)$ which indicates the tablet had good mechanical resistance.

\section{Dissolution rate study}

Table 7: Dissolution data of Tablets of Tadalafil

\begin{tabular}{|c|c|c|c|c|c|c|c|c|c|}
\hline \multirow{2}{*}{$\begin{array}{c}\text { Time } \\
(\mathbf{m i n})\end{array}$} & \multicolumn{10}{|c|}{ Formulation Batches } \\
\cline { 2 - 10 } & $\begin{array}{c}\text { F1 } \\
(\boldsymbol{\%})\end{array}$ & $\begin{array}{c}\text { F2 } \\
(\boldsymbol{\%})\end{array}$ & $\begin{array}{c}\text { F3 } \\
(\boldsymbol{\%})\end{array}$ & $\begin{array}{c}\text { F4 } \\
(\mathbf{\%})\end{array}$ & $\begin{array}{c}\text { F5 } \\
(\mathbf{\%})\end{array}$ & $\begin{array}{c}\text { F6 } \\
(\boldsymbol{\%})\end{array}$ & $\begin{array}{c}\text { F7 } \\
(\boldsymbol{\%})\end{array}$ & $\begin{array}{c}\text { F8 } \\
(\mathbf{\%})\end{array}$ & $\begin{array}{c}\text { F9 } \\
(\boldsymbol{\%})\end{array}$ \\
\hline 5 & 43.55 & 37.8 & 34.05 & 47.3 & 35.95 & $\mathbf{4 3 . 5 5}$ & 34.05 & 39.75 & 47.3 \\
\hline 10 & 53.05 & 51.15 & 39.75 & 51.15 & 49.25 & $\mathbf{5 3 . 0 5}$ & 45.45 & 53.05 & 53.05 \\
\hline 15 & 66.30 & 66.3 & 56.8 & 64.35 & 62.55 & $\mathbf{6 8 . 2 5}$ & 54.9 & 58.9 & 66.3 \\
\hline 20 & 72.00 & 73.80 & 70.15 & 75.8 & 69.75 & $\mathbf{7 7 . 6 0}$ & 66.3 & 72 & 75.8 \\
\hline 25 & 80.75 & 77.40 & 77.40 & 83.4 & 89.00 & $\mathbf{8 9 . 1 0}$ & 89.1 & 80.75 & 80.75 \\
\hline 30 & 85.05 & 79.65 & 89.1 & 94.8 & 92.9 & $\mathbf{9 8 . 6}$ & 96.75 & 89.7 & 89.70 \\
\hline
\end{tabular}

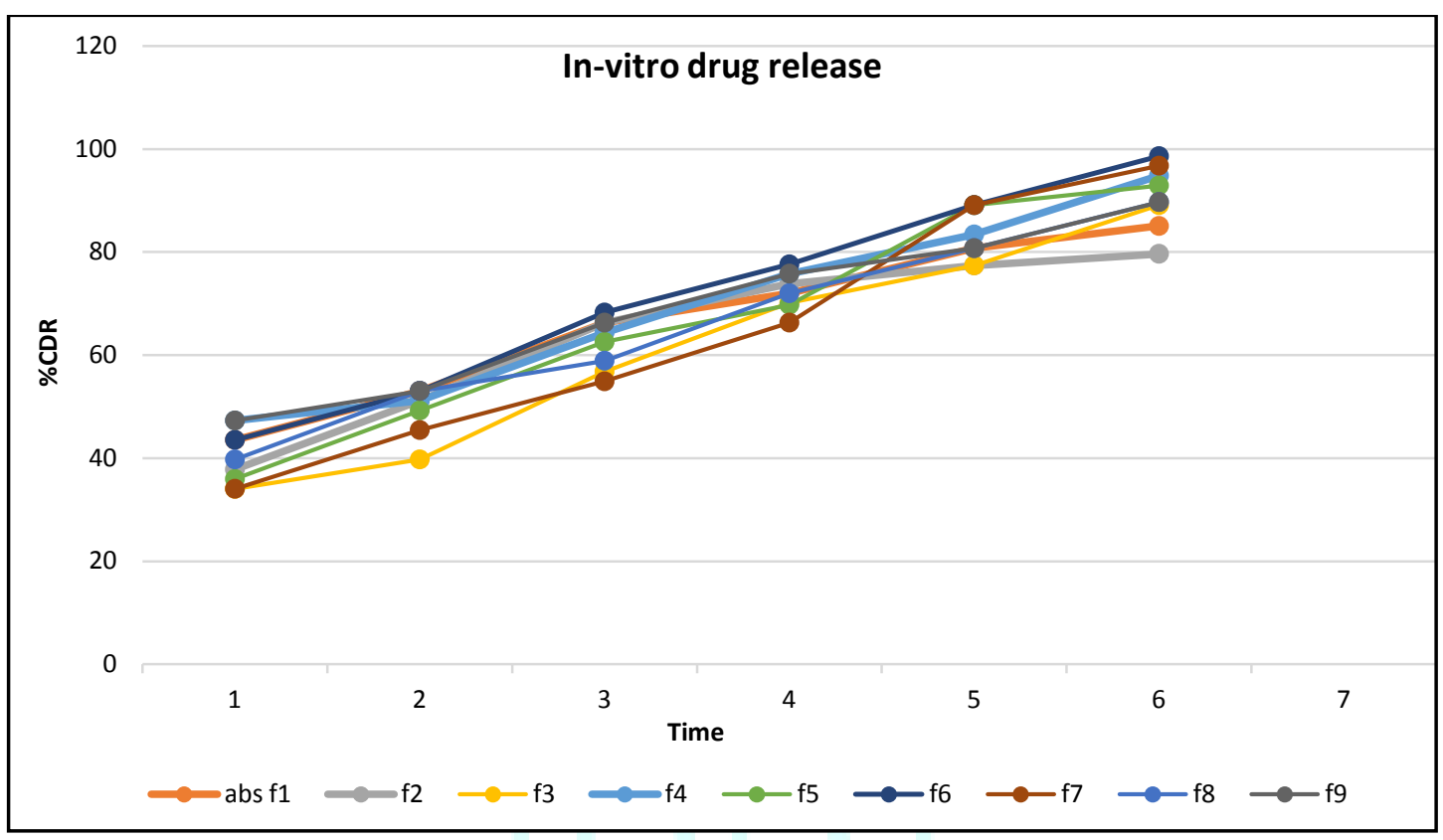

Figure 6: Dissolution Profile of Tablet (F1-F9)

\section{Dissolution Kinetics:}

\section{Release kinetics studies}

The dissolution kinetics of optimized batch was applied to various dissolution models such as Zero order, First order, Higuchi, Korsemayer- peppas. The best fitted model gives the highest R2 value and least slope value. Thus, zero order model fits best for the dissolution data of the optimized batch as it showed the highest value for R2.

Table 8: Drug Release kinetics of optimized batch

\begin{tabular}{|c|c|c|}
\hline S. N. & Models & $\mathrm{R}^{2}$ Value \\
\hline 1 & Zero Order & 0.9861 \\
2 & First Order & 0.9539 \\
\hline 3 & Higuchi & 0.9608 \\
4 & Korsemayer-peppas & 0.7825 \\
\hline
\end{tabular}

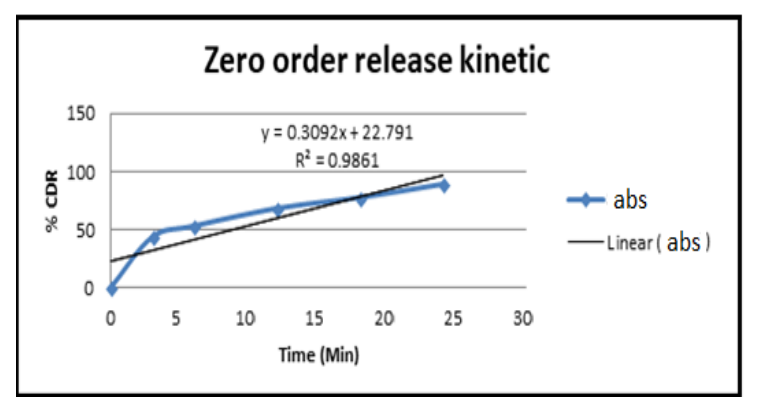

Figure 7: Model Graph for Zero Order Kinetics

\section{CONCLUSION}

There is enhancement of the solubility rate if tadalafil by solid dispersion with Poloxamer 188 prepared by solvent evaporation method. The drug was characterized for its organoleptic properties and the results obtained collaborated with literature. The IR spectra and DSC Thermogram also confirmed the drug's identity and purity. The compatibility studies of the drug and 
polymers showed that there was no incompatibility between them. Melting point of tadalafil was found to be $298^{\circ} \mathrm{C}$ which was within the literature range 301$302^{\circ}$ C.In- vitro release was studied using USP dissolution apparatus at a constant temperature of $37 \pm$ $0.5^{\circ} \mathrm{C}$ at RPM 50 for a period of $30 \mathrm{~min}$ shows increase in drug release. Wet granulation method showed that, the desirable flow properties for the compression into tablets. Tablets were prepared using wet granulation method resulted into simple, cheap, more suitable method for the manufacturing immediate release dosage form.

\section{REFERENCES}

1. Brunton L, editor. Goodman \& Gillman's The Pharmacological Basis of Therapeutics. 11th ed. New York: McGraw-hill Medical Publishing Division; 2006: p.813.

2. Walker R. Clinical Pharmacy and Therapeutics. 5th ed. Edinburgh: Elsevier Ltd.; 2012: p.295-6.

3. Jaimini M and Rawat S: A Review on Immediate Release Drug Delivery System, Res. J. Pharm., Biol. Chem. Sci, 2013; 4(2):1721-1730.

4. Brahmankar D.M, Jaiswal Sunil B. Biopharmaceutics and pharmacokinetics, A treatise. Absorption of drugs. Edn 2, Vallabh Prakashan, Delhi 2009: p.24-27.

5. Desai K.G.H, Kulkarni A.R, Aminabhavi TM: Solubility of Rofecoxib in the presence of methanol, ethanol and sodium lauryl sulfate at $(298.15,303.15$ and 308.15$) \mathrm{k}$. Journal of Chem. Eng, 2003; 48(4):942-945.

6. Liu C. and Desai K.G. H: Solubility of Valdecoxib in the presence of Ethanol and Sodium lauryl sulfate at (298.15, 303.15 and 308.15) k. Journal of Chem. Eng. Data, 2004; 49(6):1847-1850.

7. Desai K.G.H. and Park H. J: Solubility studies of Valdecoxib in the presence of carriers, co-solvents and surfactants. Drug Dev Res, 2004; 62(1): 41-48.

8. Ford JL. The current status of solid dispersions. Pharm Acta Helv, 1986; 61:69-88.

9. Mayersohn M and Gibaldi M, J, Pharm. Sci., 1996; 55:1323.

10. Uekama K, J.Pharm.Soc., 1980; 100:903

11. Ford JL. The current status of solid dispersions. Pharm Acta Helv., 1983; 58:1

12. Pouton CW. Formulation of poorly water-soluble drugs for oral administration: Physicochemical and physiological issues and the lipid formulation classification systems, Eur J Pharm Sci, 2006; 29:278-87.

13. Craig DQ. The mechanism of drug release from solid dispersions in water-soluble polymers, Int J Pharm, 2002; 231:131-44.

14. Chiou WL, Riegelman S. Pharmaceutical applications of solid dispersion systems, J Pharm Sci, 1971; 60:1281-302.

15. Jain AK, Solubilisation of Indomethacin Using Hydrotropes For Aqueous Injection, Eur J Pharm Biopharm, 2008; 68:701714.

16. Agrawal S, Pancholi SS, Jain NK, Agrawal GP. Hydrotropic Solubilisation of Nimesulide for Parenteral Administration Int J Pharm, 2004; 274:149-155.

17. https://www.drugbank.ca/drugs/DB00820.

18. https://pubchem.ncbi.nlm.nih.gov/compound/Tadalafil\#sectio $\mathrm{n}=$ Physical-Description.

19. Mohammad Yunoos, D. Gowri Sankar, B. Pragati Kumar, UV Spectrophotometric method for the estimation of tadalafil in bulk and tablet dosage form, E-journal of chemistry, 2010: $7(3)$. 